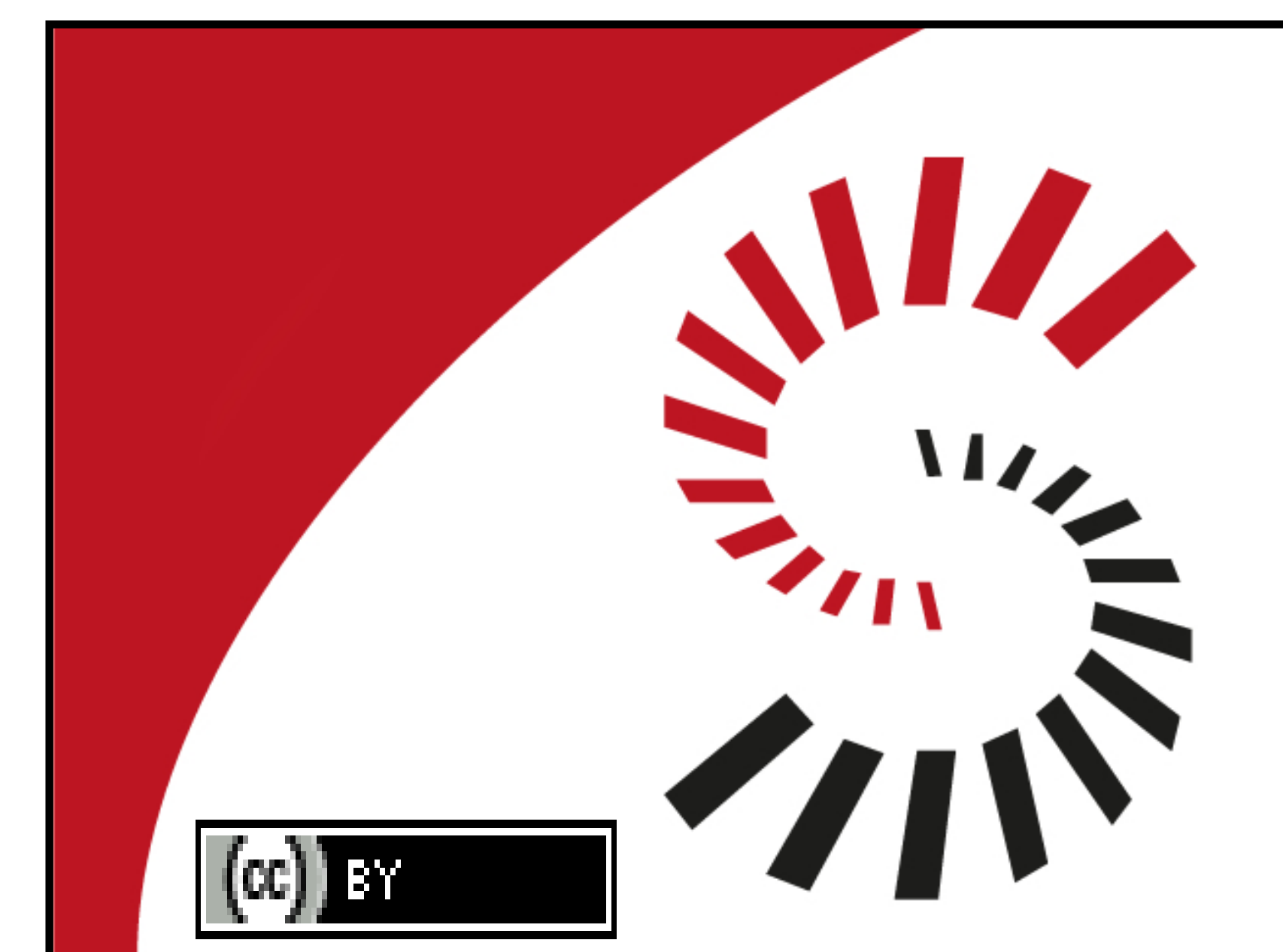

SimTec

SIMPÓSIO DOS PROFISSIONAIS DA UNICAMP

\title{
GESTÃO DOCUMENTAL DOS ARQUIVOS PESSOAIS DOS SERVIDORES DAS CARREIRAS PAEPE E DOCENTE DA FACULDADE DE CIÊNCIAS MÉDICAS.
}

Introdução:

THIAGO SANCASSANI, IVAN LUIZ MARTINS FRANCO DO AMARAL, SALETE GOBI CHIULLE DIAS, MONICA MARIA VIEIRA DE VITO, FERNANDA FÁTIMA SANCHES, FLÁVIA SOARES

FCM - FACULDADE DE CIENCIAS MEDICAS;DIRADM - DIRETORIA DE APOIO ADMINISTRATIVO;AP - SECAO DE ADMINISTRACAO DE PESSOAL contratos, pedidos de férias, licença prêmio, entre outros. Em decorrência da ausência de espaço, o arquivo estava armazenado em uma pequena sala, localizado abaixo da escada do prédio principal da Faculdade. Com o advento dos sistemas digitais de armazenamento de dados dos servidores, além da aprovação, em 2010, da Tabela Temporalidade de Documentos da DGRH, apresentou-se viável iniciar uma política de gestão documental dos arquivos de seus colaboradores.

\section{Metodologia:}

O trabalho foi desenvolvido pelo $\mathrm{RH}$ com orientações do Centro de Memória/FCM. Consistiu inicialmente em analisar as pastas armazenadas, conforme a Tabela de Temporalidade da DGRH, sendo posteriormente separados os documentos que cumpriram o prazo. Os conjuntos com pendencia judicial foram higienizados e conservados na secretaria da área, e os demais conjuntos foram eliminados após preenchimento e aprovação da Relação de Eliminação de Documentos.

\section{Resultados}

O resultado de toda essa minuciosa análise resultou na liberação de 10 arquivos metálicos. Os documentos foram enviados para seu adequado descarte, conforme se pode observar nas fotos, e aqueles que necessitaram de guarda, foram acondicionados em caixas devidamente identificadas para eventual consulta. Depois de desenvolvido todo esse trabalho, somente os documentos realmente necessários ficaram nos dossiês dos servidores ativos. Com o término do processo de gestão documental, a política de arquivamento foi alterada para um processo bem detalhado; atualmente, cada documento é analisado com rigor para que se identifique a necessidade de sua guarda, conforme Tabela de Temporalidade. Com essa ação, os documentos dos servidores são arquivados, preferencialmente, em seus devidos processos - tais como Vida Funcional, Afastamento, Contagem de Tempo, entre outros.

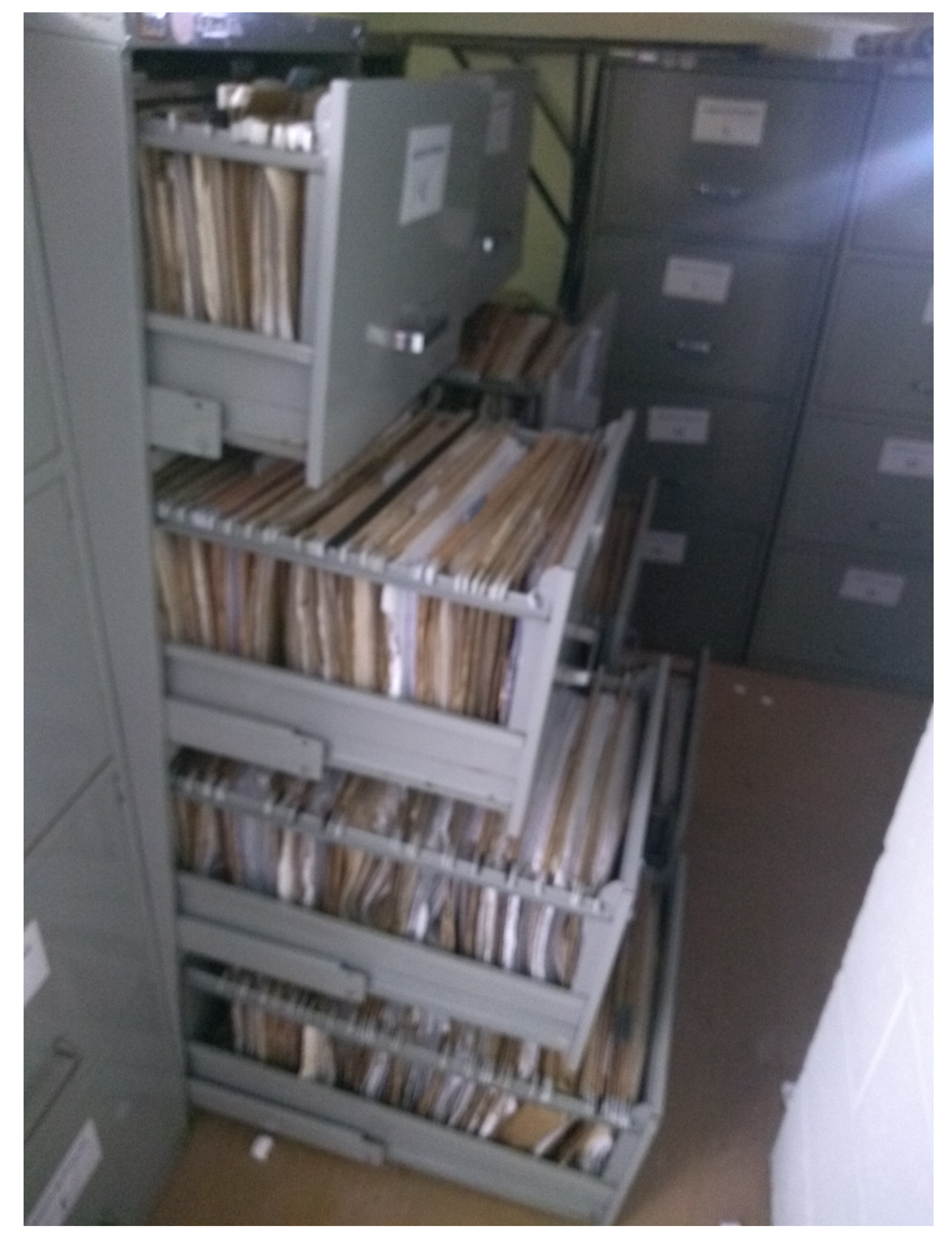

Legenda: Armários Superlotados

\section{Considerações finais:}

O projeto trouxe significativos benefícios para todo o setor. Através dessas ações, conseguimos liberar espaços físicos que antigamente estavam tomados de armários. Pudemos ter também uma visão mais adequada de nossos procedimentos e identificar que muitos documentos estavam sendo arquivados de forma equivocada. 